\title{
HUBUNGAN TINGKAT KESEGARAN JASMANI DENGAN KECERDASAN SISWA KELAS VII SMP PEMBANGUNAN LABORATORIUM UNIVERSITAS NEGERI PADANG
}

\begin{tabular}{|c|c|}
\hline & $\begin{array}{c}\text { Oleh } \\
\text { Siska } \\
\text { STKIP Rokania } \\
\text { siskazb36@gmail.com } \\
\end{array}$ \\
\hline Article History & Abstract \\
\hline $\begin{array}{ll}\text { Received } & \text { : March } 2019 \\
\text { Accepted } & \text { : June } 2019 \\
\text { Published } & \text { : July } 2019\end{array}$ & $\begin{array}{l}\text { This research aims to know the level of intelligence of } \\
\text { students of grade VII SMP Development Laboratory of } \\
\text { Padang State University, the level of physical freshness of } \\
\text { class VII students SMP Development Laboratory of Padang }\end{array}$ \\
\hline $\begin{array}{l}\text { Keywords } \\
\text { Physical freshness, intelligence }\end{array}$ & $\begin{array}{l}\text { State University, and relationship level Physical freshness } \\
\text { with the intelligence of class VII SMP Pembangunan } \\
\text { Laboratories of Padang State University. This research is } \\
\text { correlational. The population is a grade VII student of the } \\
\text { Padang State University laboratories which amounted to } 203 \\
\text { people. Sampling techniques are purposive sampling with a } \\
\text { total of } 30 \text { people. To measure the level of physical freshness } \\
\text { used TKJI test (Indonesian physical freshness test) for sons } \\
\text { and daughters aged } 13-15 \text { years and the assessment of } \\
\text { Intelligence (IQ) is obtained from the Intellegence (IQ) test } \\
\text { in cooperation with the Department of Counseling Faculty of } \\
\text { Science Education UNP. Data analysis is done using SPSS } \\
\text { 13.0. Based on the results of research findings known } \\
\text { average (mean) physical freshness of } 12.87 \text { and its deviation } \\
\text { (Stardar deviation) } 2.12 \text {, while the average Intellegence (IQ) } \\
\text { is } 96.77 \text { and its deviation is } 6.93 \text {. From the results of a } \\
\text { correlation analysis of research acquired correlation } \\
\text { coefficient } r=0.394 \text { with significance level 0.031 meaning } \\
\text { that there is a significant relationship between the level of } \\
\text { physical freshness with the intelligence of junior secondary } \\
\text { students development class VII Padang State University } \\
\text { Laboratory. }\end{array}$ \\
\hline
\end{tabular}

\begin{abstract}
Abstrak
Penelitian ini bertujuan untuk mengetahui tingkat kecerdasan siswa kelas VII SMP Pembangunan Laboratorium Universitas Negeri Padang, tingkat kesegaran jasmani siswa kelas VII SMP Pembangunan Laboratorium Universitas Negeri Padang, dan hubungan tingkat kesegaran jasmani
\end{abstract}


dengan kecerdasan siswa kelas VII SMP Pembangunan Laboratorium Universitas Negeri Padang. Penelitian ini merupakan korelasional. Populasi adalah siswa kelas VII SMP Pembangunan Laboratorium Universitas Negeri Padang yang berjumlah 203 orang. Teknik pengambilan sampel adalah purposive sampling dengan jumlah sampel sebanyak 30 orang. Untuk mengukur tingkat kesegaran jasmani digunakan tes TKJI (Tes Kesegaran Jasmani Indonesia) untuk putra dan putri umur 13-15 tahun dan penilaian hasil kecerdasan (IQ) diperoleh dari tes Intellegence (IQ) yang bekerja sama dengan Jurusan Bimbingan Konseling Fakultas Ilmu Pendidikan UNP. Analisa data dilakukan dengan menggunakan SPSS 13.0.

Berdasarkan hasil penemuan penelitian diketahui rata-rata (mean) kesegaran jasmani sebesar 12,87 dan simpangan bakunya (stardar deviasi) 2,12, sedangkan ratarata Intellegence (IQ) adalah 96,77 dan simpangan bakunya 6,93. Dari hasil analisa korelasi penelitian diperoleh koefisien korelasi $\mathrm{r}=0,394$ dengan tingkat signifikansi 0,031 yang berarti bahwa terdapat hubungan yang signifikan antara tingkat kesegaran jasmani dengan kecerdasan siswa SMP kelas VII Pembangunan Laboratorium Universitas Negeri Padang. 


\section{A. Pendahuluan}

Kecerdasan atau intelegensi adalah istilah umum yang digunakan untuk menjelaskan sifat pikiran yang mencakup sejumlah kemampuan, seperti kemampuan menalar, merencanakan, memecahkan masalah, berpikir abstrak, memahami gagasan, menggunakan bahasa, dan belajar. Kecerdasan erat kaitannya dengan kemampuan kognitif yang dimiliki oleh individu. "Masyarakat umum mengenal intelegensi sebagai istilah yang mengambarkan kecerdasan, kepintaran, atau untuk memecahkan problem yang dihadapi" (Saifudin dalam Mudjiran, dkk 2007:57). Kecerdasan dapat diukur dengan menggunakan alat psikometri yang biasa disebut sebagai tes IQ (Intelligence Quotient). Secara ilmiah kecerdasan ini bersumber dari otak manusia yang disebut neucortex.

"Setiap manusia mempunyai pola pikir yang berbeda karena intelegensi merupakan herediter yang bersifat individu di samping latar belakang pendidikan dan sosial manusia itu sendiri. Perbedaan kecerdasan ditentukan oleh pendidikan dan pengajaran yang telah diterima seseorang" (Carly dalam Buchori, 1970:48). Orang yang mempunyai intelegensi tinggi akan mempunyai kemampuan dalam memecah- kan bermacam-macam permasalahan dalam situasi tertentu, termasuk di dalamnya masalah belajar, beradaptasi dengan lingkungan baru. Seseorang yang mempunyai intelegensi lebih tinggi akan lebih cepat memecahkan suatu persoalan bila dibandingkan dengan orang yang mempunyai intelegensi lebih rendah. Menurut Prayitno (2006:56) “intelegensi adalah kemampuan memfungsikan mental dalam berbagai bentuk seperti: berfikir logis, memahami, mengingat, menerapkan berbagai konsep dan prinsip dalam situasi yang tepat, memahami hubungan taksonomi, memanipulasi bilangan atau berhitung, memusatkan perhatian, dan mengkoordinasikan gerakan motorik. Pada umumnya kemampuan intelegensi yang paling tinggi adalah kemampuan memecahkan masalah, berintekrasi dengan lingkungan sosial non sosial dengan baik dan kemampuan mencipta atau kreativitas".

Soetopo (1983:77) menyatakan beberapa faktor yang mempengaruhi IQ seperti: “(1) faktor pembawaan, (2) faktor kematangan, (3) faktor pembentukan. Faktor pembentukan ini berasal dari 
kegiatan olah fisik menimbulkan kesegaran jasmani seseorang”. Gardner dalam Sarwono (2009:158) menemukan “ Theory of Multiple Intelligences”, ada beberapa inteligensi adalah “ 1) kecerdasan bahasa (linguistic) (2) logikamatematik (logical-mathematical) ruang (spatial) (4) gerak tubuh (bodilykinesthetic) (5) musik (musikal) ,(6) antar pribadi (interpersonal), (7) ke dalam diri (intrapersonal), dan (8) kecerdasan tentang alam (naturalistic intelligence)". Orang yang memiliki kecerdasan kinestetik seseorang mempunyai bakat dalam mengendalikan gerak tubuh dan keterampilan dalam menangani benda. Kecerdasan kinestetik-jasmani tingkat tinggi seperti berjalan kaki, berlari, berenang, atau berperahu adalah orangorang yang cekatan, indra perabanya sangat peka, tidak bisa tinggal diam, dan berminat atas segala sesuatu.

Belahan otak dibagi menjadi dua bagian bagian yaitu belahan otak kiri (left hemisphere) dan belahan otak kanan (right hemisphere). Belahan otak kiri berkenaan dengan kemampuan berfikir ilmiah, kritis, logis, konvergen, deduktif, rasional, eksplisit, historikal, abstrak, dan linear; sedangkan otak kanan berkenaan dengan fungsi yang nonlinear, nonverbal, holistis, emosional, imajinatif, artistik, simbolis, intuitif, kreatif, humanistis bahkan mistik (Rachmawati, 2010:26). Menurut Saifuddin dalam Nunuk (2010) neuroimaging dapat dianggap pemetaan otak. Pemetaan otak dapat dipahami sebagai bentuk tinggi neuroimaging, memproduksi pencitraan otak yang ditambah dengan hasil pemrosesan atau analisis data (pencitraan ataupun nonpencitraan) tambahan, seperti peta yang memproyeksikan (ukuran) perilaku ke regio otak "Penelitian dengan teknik neuroimaging membuktikan bahwa volume otak berkorelasi dengan IQ. Bukti ini didapat dengan mengukur ukuran helm tentara AS yang sedang mengikuti training dan dibandingkan dengan IQ-nya. Walaupun demikian korelasi tersebut cukup kecil".

Menurut Oktaviani (2008:1) dalam penelitiannya diketahui bahwa kesegaran jasmani mempunyai pengaruh dan memegang peran penting dalam mengembangkan pola pikir seseorang, bila tingkat kesegaran jasmani seseorang tinggi maka daya pikir atau tingkat kecerdasan seseorang cenderung meningkat pula dibandingkan dengan orang yang tingkat 
kesegaran jasmani rendah. Berdasarkan penelitian tersebut, diperoleh kesimpulan bahwa besarnya konstribusi tingkat kesegaran jasmani terhadap kecerdasan siswa SMU Pertiwi Kota Padang sebesar $58,8 \%$.

Dari penelitian Oktaviani dan teori Edward Gardner mengungkapkan kesegaran jasmani berpengaruh dan memegang peranan penting dalam mengembangkan pola pikir seseorang. Jika tingkat kesegaran jasmani seseorang tinggi maka daya pikir atau tingkat kecerdasan seseorang cenderung meningkat dibandingkan dengan orang yang tingkat kesegaran jasmaninya rendah. Dengan demikian IQ yang dimiliki seseorang memberikan pengaruh terhadap kemampuan untuk memperoleh banyaknya keterampilan dan lebih mudah belajar serta adanya kecendrungan untuk mendapatkan hasil yang dimiliki orang tersebut. Orang yang memiliki kesegaran jasmani yang baik akan memiliki respon atau refleks yang baik, dimana orang dianggap intelegen apabila responnya merupakan respon yang baik atau sesuai dengan stimulus yang diterimanya.

Dalam aktifitas belajar siswa, kesegaran jasmani diperlukan dalam meningkatkan prestasi siswa dalam belajar. Karena, dengan kesegaran jasmani yang baik maka siswa akan memperoleh daya tahan, kekuatan, kecepatan dan kelincahan sehingga memiliki pola pola pikir yang baik, sehingga mempunyai kecerdasan yang baik pula. Apabila seseorang tidak mempunyai kesegaran jasmani yang bagus dalam belajar, maka siswa akan sering merasa letih, lelah, dan tidak semangat dalam proses belajar mengajar berlangsung. Sehingga menyebabkan penurunan minat dan prestasi siswa dalam belajar.

Pendidikan jasmani olahraga dan kesehatan (penjasorkes) merupakan salah satu mata pelajaran yang wajib diikuti siswa pada SMP Pembangunan Laboratorium Universitas Negeri Padang (SMP PEMB. LAB UNP). Mata pelajaran Penjasorkes dapat meningkatkan kondisi fisik kesegaran jasmani seseorang, akan tetapi pelajaran ini sering diremehkan dengan pemberian waktu belajarnya 2 x 40 menit ( 2 jam pelajaran), padahal penjaskes sangat penting dalam meningkatkan kesegaran jasmani. Berdasarkan data yang diperoleh pada survey awal diketahui nilai rata-rata hasil belajar siswa kelas VII A SMP Pembangunan Laboratorium UNP 
adalah 57,58. Nilai ini tergolong rendah. Mengingat adanya penelitian sebelumnya pada siswa SMU yang menyatakan adanya konstribusi antara kesegaran jasmani dengan kecerdasan, maka diduga rendahnya hasil belajar pada siswa SMP akibat dari rendahnya tingkat kesegaran jasmani siswa tersebut, yang lebih lanjut mempengaruhi tingkat kecerdasan siswa kelas VII A SMP Pembangunan Laboratorium Universitas Negeri Padang.

Merujuk pada penelitian Oktaviani dengan sampel siswa SMU maka peneliti tertarik untuk melihat pengaruh ini terhadap siswa SMP. Berdasarkan uraian di atas, maka peneliti ingin mengetahui seberapa besar tingkat kesegaran jasmani berkorelasi dengan tingkat kecerdasan pada SMP Laboratorium UNP. Berdasarkan fenomena yang muncul inilah penulis tertarik untuk meneliti dengan judul : "Hubungan Tingkat Kesegaran Jasmani dengan kecerdasan siswa kelas VII SMP Pembangunan Laboratorium UNP”.

\section{B. Metode Penelitian}

Penelitian ini merupakan penelitian korelasional dengan populasi adalah siswa kelas VII SMP Pembangunan
Laboratorium Universitas Negeri Padang yang berjumlah 203 orang. Teknik pengambilan sampel yang digunakan adalah purposive sampling dengan jumlah sampel sebanyak 30 orang. Untuk mengukur tingkat kesegaran jasmani digunakan tes TKJI (Tes Kesegaran Jasmani Indonesia) untuk putra dan putri umur 13-15 tahun dan penilaian hasil kecerdasan (IQ) diperoleh dari tes Intellegence (IQ) yang bekerja sama dengan Jurusan Bimbingan Konseling Fakultas Ilmu Pendidikan UNP. Analisa data dilakukan dengan menggunakan SPSS 13.0.

\section{C.Hasil Penelitian dan Pembahasan}

\section{Hasil Penelitian}

'Dalam bab ini akan dibahas hasil pengukuran tes kesegaran jasmani dan Intellegence Quotient pada siswa kelas VII SMP Pembangunan Laboratorium Universitas Negeri Padang. Untuk lebih jelasnya masing-masing deskripsi data tersebut dapat terlihat sebagai berikut.

a. Kesegaran Jasmani

Data variabel kesegaran jasmani diperoleh dari 30 responden melalui tes kesegaran jasmani Indonesia yang meliputi : 1) Lari cepat 50 meter umur 13- 
15 tahun, 2) Tes gantung angkat tubuh untuk putra umur 13-15 tahun dan gantung siku tekuk untuk putri 13-15, 3) . Baring duduk 60 menit (sit up) umur 13-15 tahun, 4) Loncat tegak ; dan 5) Lari jarak menengah 1000 meter putra dan 800 meter untuk putri. Berdasarkan hasil pengukuran dari 30 orang siswa SMP kelas VII A Pembangunan Laboratorium Universitas Negeri Padang yang dijadikan sampel diperoleh jumlah nilai berdasarkan norma tingkat kesegaran jasmani tertinggi untuk tingkat kesegaran jasmani adalah sebesar 16 dan terendah 7 sedangkan ratarata (mean) sebesar 12,87, nilai tengah (median) adalah 14,00. sementara itu nilai sering muncul (Modus) yang diperoleh dalam penelitian ini adalah 14,00 dengan simpangan baku (standar deviasi) sebesar 2,12 (data terlampir dilampiran 5). Untuk lebih jelasnya dapat dilihat distribusi frekuensi di bawah ini:

Tabel 1.

Tingkat Kesegaran Jasmani Siswa SMP Kelas VII Pembangunan Laboratorium UNP

\begin{tabular}{|c|c|c|c|}
\hline Klasifikasi & $\begin{array}{c}\text { Jumlah } \\
\text { Nilai }\end{array}$ & Frekuensi & Persentase \\
\hline $\begin{array}{c}\text { Baik } \\
\text { sekali }\end{array}$ & $22-25$ & 0 & 0,00 \\
\hline Baik & $18-21$ & 0 & 0,00 \\
\hline Sedang & $14-17$ & 16 & 53,33 \\
\hline Kurang & $10-13$ & 12 & 40,00 \\
\hline
\end{tabular}

\begin{tabular}{|c|c|c|c|}
\hline $\begin{array}{c}\text { Kurang } \\
\text { Sekali }\end{array}$ & $5-9$ & 2 & 6,67 \\
\hline Jumlah & - & 30 & 100 \\
\hline
\end{tabular}

Sumber : Pengolahan Data Primer

Berdasarkan tabel 1 di atas, dari 30 siswa SMP kelas VII A Pembangunan Laboratorium Universitas Negeri Padang tidak satu orang pun siswa memiliki kesegaran jasmani dalam klasifikasi baik dan baik sekali. Sebanyak 16 orang ( 53,33\%) siswa memiliki kesegaran jasmani yang sedang, 12 orang ( 40,00\% ) memiliki kesegaran jasmani kurang dan 2 orang $(6,67 \%)$ memiliki kesegaran jasmani kurang sekali.

Untuk lebih jelasnya distribusi frekuensi hasil tes kesegaran jasmani siswa kelas VII SMP Pembangunan Laboratorium Universitas Negeri Padang dapat dilihat pada gambar berikut :

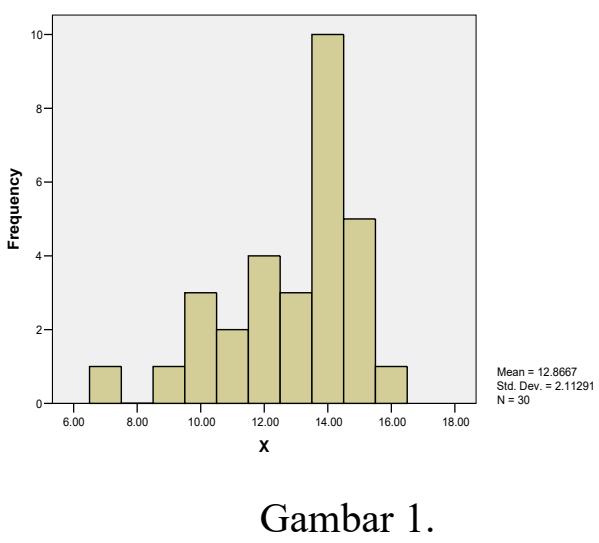

Histogram Distribusi Frekuensi Kesegaran Jasmani Siswa 


\section{b. Hasil kecerdasan siswa}

Data variabel kecerdasan diperoleh dari tes IQ siswa SMP kelas VII Pembangunan Laboratorium Universitas Negeri Padang. Dari sebaran data diperoleh nilai IQ tertinggi adalah 111 dengan kategori di atas rata-rata dan nilai terendah sebesar 90 dengan kategori ratarata. Dari sebaran data ini diperoleh skor rata-rata hasil IQ sebesar 96,77 dan masuk dalam kategori rata-rata, nilai tengah sebesar 94 dan nilai yang banyak muncul adalah 90 serta standar deviasi sebesar 6,93. Untuk lebih jelasnya gambaran mengenai variabel hasil IQ siswa dapat dilihat tabel sebagai berikut :

Tabel 2.

Distribusi Frekuensi $I Q$ Siswa

\begin{tabular}{|c|c|c|c|}
\hline Kategori & Skor & $\begin{array}{c}\text { Fre } \\
\text { kuensi }\end{array}$ & $\begin{array}{c}\text { Per } \\
\text { sentase }\end{array}$ \\
\hline Cerdas & $>120$ & 0 & 0,00 \\
\hline $\begin{array}{c}\text { Di atas } \\
\text { rata-rata }\end{array}$ & $111-120$ & 2 & 6,70 \\
\hline Rata-rata & $90-110$ & 28 & 93,30 \\
\hline Jumlah & & 30 & $\%$ \\
\hline
\end{tabular}

Sumber : Pengolahan Data Primer

Berdasarkan pada tabel distribusi frekuensi IQ siswa SMP kelas VII Pembangunan Laboratorium UNP di atas dapat disimpulkan bahwa dari 30 orang responden tidak seorang pun siswa yang memiliki kategori IQ siswa yang berada pada kategori cerdas. Namun sebanyak 28 orang $(93,30 \%)$ dikategorikan rata-rata dan 2 orang $(6,70)$ siswa mempunyai IQ dengan kategori di atas rata-rata. Untuk lebih jelasnya dapat dilihat gambar histogram distribusi di bawah ini :

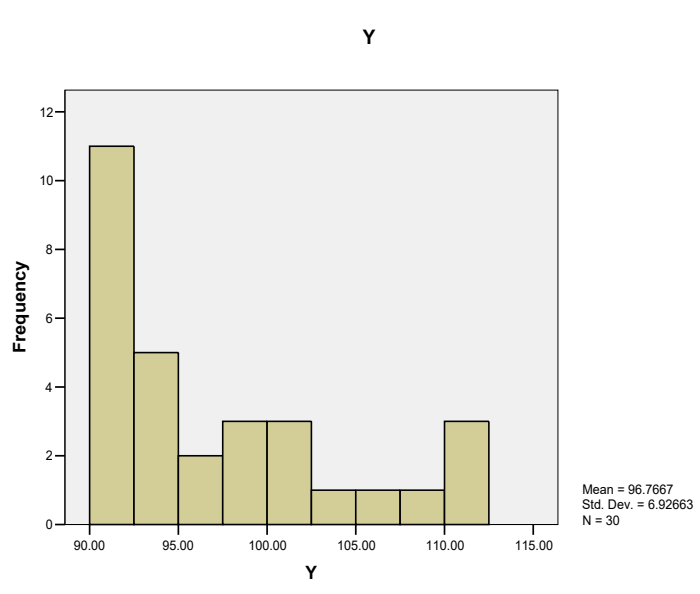

Gambar 2. Histogram $I Q$ Siswa

\section{Uji Normalitas}

Sebelum dilakukan uji hipotesis dengan menggunakan analisis korelasi terlebih dahulu dilakukan uji normalitas terlebih dahulu. Pengujian normalitas data dimaksudkan untuk menguji asumsi bahwa data berdistribusi normal. Uji normalitas dilakukan dengan menggunakan uji Kolmogorov Smirnov. Sebaran data berdistribusi normal jika nilai Asymp. Sig $>0.05$. Hasil perhitungan uji normalitas dapat dilihat pada 
rangkuman tabel berikut

Tabel 3.Rangkuman Uji Normalitas

\begin{tabular}{|c|c|c|c|}
\hline Variabel & $\begin{array}{c}\text { Kolmogorov } \\
\text { Smirnov } Z\end{array}$ & $\begin{array}{l}\text { Asymp. } \\
\text { sig }\end{array}$ & Keteranga \\
\hline $\mathrm{X}$ & 1,301 & 0,068 & Normal \\
\hline $\mathrm{Y}$ & 1,033 & 0,237 & Normal \\
\hline
\end{tabular}

Sumber : Pengolahan Data Primer

Dari tabel di atas dapat dilihat bahwa nilai asymp sig. untuk variabel kesegaran jasmani siswa diperoleh sebesar $0,068>0,05$. Sedangkan pada variabel IQ siswa diperoleh nilai asymp. Sig. sebesar $0,237>0,05$. dengan demikian dapat dinyatakan bahwa data kedua variabel dalam penelitian ini berdistribusi normal.

\section{Uji Hipotesis}

Hipotesis penelitian yang diajukan adalah 'Terdapat Hubungan yang Signifikan Antara Tingkat Kesegaran Jasmani dengan IQ Pada Siswa SMP Kelas VII Pembangunan Laboratorium Universitas Negeri Padang”. Hipotesis ini dianalisis dengan koefisien Correlation Product Moment dengan pengujian keberartian menggunakan taraf signifikansi 0,05 .

Hipotesis uji statistik yang diajuakan sebagai berikut ;

Ho $=$ Tidak terdapat hubungan yang signifikan antara tingkat kesegaran jasmani dengan IQ pada siswa SMP kelas VII Pembangunan Laboratorium Universitas Negeri Padang

$$
\mathrm{Ha}=\text { Terdapat hubungan yang }
$$
signifikan antara tingkat kesegaran jasmani dengan IQ pada siswa SMP kelas VII Pembangunan Laboratorium Universitas Negeri Padang

Dasar pengambilan keputusan adalah :

Jika nilai signifikan $>0,05$ Ho diterima, Ha ditolak

Jika nilai signifikan $<0,05$ Ho ditolak, Ha ditrima

Hasil analisis hipotesis ini terangkum pada tabel di bawah ini.

Tabel 4.

Rangkuman Hasil Analisis Korelasi X-

\begin{tabular}{|c|c|c|c|c|}
\hline \multirow{2}{*}{ Kore } & & Koefisien & & \\
lasi & $\mathbf{N}$ & Korelasi & Sig. & Keterangan \\
& & $(\mathbf{r})$ & & \\
\hline $\mathrm{X}-\mathrm{Y}$ & $\mathbf{3 0}$ & $\mathbf{0 , 3 9 4}$ & $\mathbf{0 , 0 3 1}$ & Signifikan \\
\hline
\end{tabular}

Berdasarkan tabel 4 menunjukkan bahwa hubungan antara tingkat kesegaran 
jasmani dengan IQ pada siswa SMP kelas VII Pembangunan Laboratorium Universitas Negeri Padang sebesar 0,394 dengan nilai signifikansi $0,031<0,05$. Berdasarkan pengambilan keputusan di atas maka maka Ho ditolak dan $\mathrm{Ha}$ diterima. dapat dikatakan bahwa terdapat hubungan yang signifikan antara tingkat kesegaran jasmani dengan IQ pada siswa SMP kelas VII Pembangunan Laboratorium Universitas Negeri Padang.

\section{Pembahasan}

$\begin{array}{ccc}\text { Hasil } & \text { analisis } & \text { korelasi } \\ \text { menggambarkan } & \text { bahwa } & \text { terdapat }\end{array}$ hubungan yang signifikan antara tingkat kesegaran jasmani (X) dengan IQ (Y) Siswa kelas VII SMP Pembangunan Laboratorium Universitas Negeri Padang.

Tingkat kesegaran jasmani merupakan suatu elemen fisik yang mempengaruhi penampilan (performance). Kondisi ini sangat bergantung pada komponen kesegaran jasmani dan motorik Brooks dalam Oktaviani, (2000:44). Sebagaimana dikemukakan Asril (1966) bahwa: "Kondisi fisik yang baik merupakan dasar utama bagi seseorang baik untuk kesegaran jasmani dan apabila bagi atlit, bagi orang bekerja dan pelajar untuk mencapai prestasi setinggitingginya".

Dari hasil kutipan sebelumnya jelas bahwa kondisi fisik seseorang mencerminkan tingkat kesegaran jasmaninya, karena dalam keadaan kondisi fisik yang baik seseorang akan dapat menyelesaikan tugas dan aktifitas sehariannya dengan efektif dan efesien.

Sementara itu menurut Saifuddin Azwar dalam (Mudjiran, dkk 2007:65) “ bahwa orang yang mempunyai kesegaran jasmani yang sehat dan segar berkemungkinan besar orang tersebut memiliki pola pikir yang baik dan luas". Dapat disimpulkan bahwa kecerdasan seseorang menentukan pola pikirnya terhadap suatu hal. Pola pikir yang baik ditentukan oleh kesegaran jasmani yang dimiliki seseorang. Dengan demikian semakin baik kesegaran jasmani seseorang akan memiliki pola pikir yang baik sehingga mempunyai kecerdasan yang baik pula. Sementara itu apabila kesegaran jasmani seseorang rendah, maka pola pikirnya juga akan sempit yang akhirnya akan mempengaruhi kecerdasannya.

Menurut Saifuddin (1996:11), orang dengan intelegensi yang tinggi akan lebih berhasil menjalankan tugas yang 
membutuhkan intelektual dan tidak dapat dipungkiri secara umum sekolah cenderung memperkenalkan siswa pada pengetahuan yang membutuhkan kemampuan intelektual. Siswa yang giat dan tekun dalam pelajaran di sekolahnya adalah anak-anak yang mempunyai tingkat kecerdasan lebih tinggi, badannya kuat, lebih sehat, mampu berlari lebih cepat serta bermain dalam suatu permainan secara lebih baik dari anak-anak yang lain.

Dalam kenyataan di lapangan hal ini dapat saja terjadi, dimana adanya siswa yang kesegaran jasmaninya kurang baik tetapi mempunyai tingkat kecerdasan yang amat baik dan begitu juga sebaliknya, ada siswa yang mempunyai tingkat kecerdasan yang kurang tetapi kesegaran jasmaninya baik.

Kesegaran tidak hanya menuntut keadaan kondisi secara fisik saja, tetapi juga menuntut keterlibatan seluruh aspek tubuh seseorang, diantaranya kemampuan berfikir (kecerdasan) yang dimiliki. Artinya bahwa kesegaran jasmani merupakan suatu kemampuan yang berhubungan dengan tingkat kecerdasan berfikir seseorang. Yang mendorong perkembangan motor skills (kecakapankecakapan jasmani) anak yang juga memungkinkan campur tangan orang tua dan guru dalam mengarahkannya yaitu perkembangan dan pertumbuhan system saraf. System saraf adalah organ halus dalam tubuh yang terdiri dari struktur jaringan serabut saraf yang sangat halus yang berpusat di central nervous system, yakni pusat sistem jaringan saraf yang ada di otak (Reber dalam Syah, 2006:18). Pertumbuhan saraf dan perkembangan kemampuannya membuat inteligensi (kecerdasan) anak meningkat dan mendorong timbulnya pola-pola tingkah laku baru, semakin baik perkembangan kemampuan sistem saraf seorang anak akan semakin baik dan beraneka ragam pula pola-pola tingkah laku yang dimilikinya seperti keterampilan dalam berolahraga, karena kinerja jasmaniah (physical ferformance) dalam aktifitas tersebut hanya akan bermutu baik apabila pelaksanaannya disertai dengan keterlibatan fungsi ranah cipta atau akal.

Pada usia 7 tahun hingga 15 tahun, perkembangan otak dan kemampuan analisanya akan semakin cepat, maksunya bahwa pada usia ini seorang anak akan mulai bisa berpikir sesuatu yang jauh lebih kompleks, hingga sampai ke wilayah hakikat dan hal-hal yang menyentuh 
wilayah keberadaan segala sesuatu. Maka bisa dikatakan bahwa sejak usia 7 tahunan, seorang anak sebenarnya sedang memasuki proses pencarian kebenaran dan hakikat kehidupan. Otak yang dianugerahkan Allah SWT kepadanya mulai berfungsi secara baik dan mulai melakukan aktifitas pencaharian dan perkembangan ini akan terus terjadi hingga masuk masa baligh dan hingga dewasa.

Dalam kegiatan motorik siswa yang dilakukan secara sadar, baik dalam kondisi statis maupun dinamis adalah hasil kinerja dari rangsangan otot yang kompleks, termasuk didalamnya komponen kesegaran jasmani (physical fitness) dan kesegaran motorik (motor fitness). Secara khusus, kesegaran motorik merupakan kemampuan keterampilan dasar motorik meliputi berbagai elemen kondisi fisik yang memberikan gambaran tentang tingkat kesegaran jasmani seseorang. Hal ini dapat dibina dan dikembangkan sampai batas kemampuan yang ada pada siswa, terutama pada masa pertumbuhan dan perkembangan. Dapat disimpulkan bahwa komponen kesegaran jasmani terdapat hubungan terhadap tingkat kecerdasan siswa serta perkembangan lainnya.

\section{D.Simpulan dan Saran}

\section{Simpulan}

Bertitik tolak dari hipotesis yang telah dikemukakan terhadap hubungan yang signifikan antara tingkat kesegaran jasmani dengan IQ siswa SMP kelas VII Pembangunan Laboratorium Universitas Negeri Padang, maka dapat ditarik kesimpulan bahwa terdapat hubungan yang signifikan antara tingkat kesegaran jasmani dengan kecerdasan dari nilai korelasi $r=0,394$ dengan signifikansi $0,031<0,05$. Orang yang mempunyai kesegaran jasmani yang tinggi akan memiliki kecerdasan yang baik. Ini berarti tingkat kesegaran jasmani berhubungan signifikan dengan tingkat IQ pada siswa SMP kelas VII Pembangunan Laboratorium Universitas Negeri Padang.

\section{Saran}

Berdasarkan pada kesimpulan di atas maka saran yang dapat dikemukakan adalah :

1. Untuk siswa agar lebih meningkatkan kesegaran jasmaninya melalui kombinasi latihan yang terprogram dan memakan makanan yang bergizi sehingga menjaga pola hidup yang 
teratur, sehingga akan berdampak terhadap aktifitas fisik yang dilakukan terutama untuk menunjang proses pembelajaran guna memperoleh hasil belajar yang diinginkan.

2. Bagi guru untuk meningkatkan materi pembelajaran terutama dalam materi peningkatan kesegaran jasmani yang dapat meningkatkan hasil belajar siswa.

3. Kepada peneliti selanjutnya untuk meneliti variabel lain yang diduga berhubungan dengan intelegensi agar dapat diketahui secara lebih mendalam lagi apa saja faktor-faktor yang mempengaruhi terhadap kesegaran jasmani siswa.

4. Kepada siswa disarankan untuk lebih memberi apresiasi terhadap mata pelajaran pendidikan jasmani dan meningkatkan minat untuk melakukan aktifitas olahraga di luar jam sekolah.

\section{Daftar Pustaka}

Arsil. 2009. Pembinaan Kondisi Fisik. Padang: Sukabina.

Buchori, Mokhtar. 1970. Psikologi Pendidikan. Bandung, Bapensi.

Mudjiran, dkk. 2007. Perkembangan Peserta Didik. Buku Bahan Belajar Pendidikan Tenaga Kependidikan Sekolah Menengah. Padang : UNP.
Oktaviani, Ade 2000 .

Skripsi."Konstribusi Kesegaran Jasmani Terhadap Kecerdasan Siswa." Padang: FIK UNP.

Prayitno, Elida. 2006. Psikologi Perkembangan Remaja. Padang: Angkasa Raya.

Rachmawati ,Yeni. 2010. Strategi Pengembangan Kreativitas Pada Anak. Jakarta : Kencana.

Saifuddin, Azwar 1996. Pengantar Psikologi Inteligensi. Pustaka Pelajar Yokyakarta.

Sarwono, Sarlito W. 2009. Pengantar pisikologi Umum. Jakarta: Rajawali Pers.

Soetopo, Hendayat. 1983. Keunikan Intelegensi Manusia. Usaha Nasional, Surabaya - Indonesia.

Syah, Muhibbin. 2006. Psikologi Belajar. Jakarta; PT Raja Grafido Persada. 